\title{
Reflections on the creative process, analysis of strategic models for the development of creative thinking in the Industrial Designer
}

\author{
Omar Eduardo Sánchez Estrada ${ }^{a}$, Mario Gerson Urbina Pérez ${ }^{b}$, Karla Georgina \\ Pérez González ${ }^{c}$ \\ ${ }^{a}$ Universidad Autónoma del Estado Mexico, Estado de México, México, \\ omarseuaem@yahoo.com.mx, ${ }^{b}$ Universidad Autónoma del Estado Mexico, Estado de Mexico, \\ México, gerson_u@hotmail.com, ${ }^{\mathrm{c}}$ Liceo Universidad Pedro de Gante, Estado de México, México, \\ graham.georginaglez@gmail.com
}

\begin{abstract}
The purpose of this article is to analyze the different strategic models to understand and identify the factors that hinder the ability to develop divergent, open thinking free of technical and emotional bias to produce new and valuable things, or to apply solutions in a wide variety of ways. Studies on creators in the field of psychology, the process of development of traditional creativity applied in the degree in industrial design of the University Center UAEM Valle de Chalco in Mexico, and analogical reasoning through the sources of inspiration for creative production were taken into account. The information theory called "Hamming Distance" was used to verify if the real estimated value is congruent with the ideal estimated value, numerical values obtained from the different strategic models for creativity and postures emitted by the teachers of the area. As a result, new parameters were obtained to educate more effectively towards a creative thinking of industrial designers.
\end{abstract}

Keywords: Strategic models,creative thinking, industrial design.

\section{Introduction}

Today academia requires finding new ways with respect to the complex task of achieving, that students develop and consolidate a creative attitude to address academic, social, or business problems, and find the greatest satisfaction in being naturally a creative individual. The aspects of creativity in design related to the problem statement and the concept of originality, aesthetics and functionality are points that are immediately recognized as 
significant in a creative process. Among different works, creativity has been defined as a person's capacity to generate a novel and appropriate product (Lubart, 1994; Sternberg and Lubart, 1996; Amabile, 1997; Sternberg, 2001). However, with such a synthesized definition, it is difficult to obtain an assertive view of the processes required to make a creative design product (Kim, Kim, Lee, and Park, 2007).

Therefore, creative problem solving in design may not have been totally reliable. Despite this, some current descriptions show that the project activity in the discipline is characterized by the occurrence of a significant event, fleeting or sudden ideas, designs, analogues; previous experiences; collaborative work between a group of students and teacher or simply the repetition of already solved dilemmas; which attend the creative development. Shroyer, Lovins, Turns, Cardella, and Atman (2018) affirm that researchers and teachers seek to formalize the different techniques to support the generation of ideas and determine their effectiveness based on the quantity, quality, and originality of those developed in design education, with the purpose of identifying indicators of creative evaluation of students in their curricular trajectory, through their different stages (Demirkan and Afacan 2012).

It should be noted that higher education communities do not share a common definition for creativity, for this reason there is less clarity in how it should be taught, evaluated or measured, however, this does not mean that it is misunderstood, there is an important number of researches that have explored almost all its dimensions, which indicates that it represents a high level of analysis, interpretation and techniques, but it remains divisive in some cases (Williams, Ostwald and Askland, 2010). Consequently, researchers and educators must agree to determine a concrete concept of creativity and find a different cognitive process to interpret and solve design problems (Kim et al. 2007).

For this reason, the research area of the degree in Industrial Design of the University Center UAEM Valle de Chalco, has developed a project based on the study of applied techniques for the development and practice of creativity, in the resolution of industrial design projects, analyzing and interpreting the teaching actions that are applied in product design workshops.

\section{Strategic models}

\section{Limited Commitment Mode (LCM)}

Creativity is defined by psychologists as "the production of novel and appropriate ideas in any field of human activity" if the generation of ideas is considered relevant, it is also 
worthwhile to work with creativity techniques that are creative and consider the problem, application context and components of a creative process. For this reason, the present study considered some strategic models of training that reflect the personal cognitive characteristics of students (Kim and Kang, 2003). Thus, creativity in design can be improved by identifying students' underlying cognitive abilities (Kim et al. 2007). Some studious of the subject identified that designers use the Limited Commitment Mode (LCM) as a strategy to solve design problems (Goel and Pirolli, 1989; Goel, 1995). Such action defines that, "when working on a particular part of the module, it does not require the designer to complete that module before starting another. You have the option of putting any module on "hold" to attend to other related or even unrelated modules and return to the first one later". In addition, it is possible to work with visual reasoning (cognitive ability) composed of: visual analysis, synthesis and representation (Kim et al., 2005a; Park et al., 2006) and constructive perception that combines perception, which is defined in psychology based on Gestalt theory, as a process characterized by processes of abstraction or search for simplicity or pregnancy and conception (Gilberto, 2004).

\section{Cognitive diversity}

Cognitive diversity in designers is seen as an advantage in solving design problems, since the generation of diverse proposals can stimulate consideration of non-obvious alternatives in the approach to design requirements (Cox and Blake, 1991, p. 50); The type of cognitive diversity was defined as "characteristics of typically preferred people and modes of information processing" (Sternberg and Grigorenko, 1997, p. 700). It has also been described as the preference for how a problem is perceived, managed and solved (Kirton, 2003).

Some studies have shown that better results are obtained in solving problems when the equipment is heterogeneous (Basadur and Head, 2001; Hoever, van Knippenberg, van Ginkel, and Barkema, 2012; Mohammed and Angell, 2004). After assessing previous research, Mello and Rentsch (2015) determined four types of cognitive diversity: 1. Stable cognitive variables that are innate features or become consistent in adulthood; 2. Cognitive variables that develop throughout life experiences are relatively stable; 3 . Studies on cognitive style diversity have demonstrated advances for teamwork as a function of creativity (Kurtzberg and Amabile, 2001).

\section{Inspiring Stimuli}

It is significant to say that the literature on design cognition indicates that, in order to avoid early fixation, designers should outline the general form of a design, before focusing attention on the details of requirements (Damle and Smith, 2009). Within that cognitive process, analog reasoning is developed, which is defined as the process by which information from a source is applied to an objective through the connection of relationships 
or representations between both ("source" and "destination") (Gentner, 1983; Moreno et al., 2014).

Although the basics are known about the neurological processes that support design cognition involving inspiring stimuli, including analogies, researchers work to make analogical reasoning in designers inductive and apply it to the creative process freely, in order to respond to the same logic in a design process. They also seek to increase the positive characteristics of design concepts through these inspiring stimuli (Fu et al., 2013; Linsey \& Viswanathan, 2014). For Goucher, Moss and Cagan (2019) the inspiring stimuli enhance inductive thinking and closely related mental processes, these stimuli, including analogies, must be presented in time and accurately to designers to be transformed into systematic inspiration for creativity.

Another line of research regarding analogies is analogical distance, considered as a continuum, i.e. a distant domain where the terms "near" and "far" are used, a close analogy would be closely related to the same domain and share significant characteristics, while a lay analogy comes from a distant domain and shares little or no characteristic. Common theories indicate that lay analogies favor the most innovative solutions (Wilson, Rosen, Nelson and Yen, 2010). However, another study has shown that close analogies are easier to apply to design problems but can lead to designer blocking (Jansson and Smith, 1991).

Another reasearch proposed the "fair point" of the analogue distance between a nearby analogy where innovation is restricted and a copy or a block is likely to occur and a very distant one where the analogy is probably located outside the problem to be useful. Additionally, the investigation of Fu et al. (2013) Does mathematical operations for the analogue distance, from the aesthetic analysis of the patents of the United states, assuring that the transfer of knowledge in the analogue distances, is a critical step to stimulate the analogies in the positive design.

In addition, there are key components in analogue reasoning such as recovering relevant information stored in long-term memory (Wharton et al., 2000) as well as selection and analysis of information (Krawczyk et al., 2008) and manipulation, new Configuration and maintenance of the information used in previous projects (Cho, Holyoak and Cannon, 2007). For Folkmann (2010) Analog reasoning can go through the structural model for imagination in design, which is composed of "matrices of ideas" since the axis of the research of the training powers of the design outlining should be directed to a A metaconceptual level that analyzes the structure of concepts and ideas, affirming that the relevant is the construction of the meaning between the interior and the outside in the flexible structures of outlining in the imagination. 
The proposed approach serves to examine some of the general factors in the transformation of an internal mental environment into an external physical representation. The proposal implies the identification of three general meta-conceptual concepts or configurations that are designer facilitators to turn ideas into products. The following configurations are within a dichotomy range. 1. Knowledge Budget: Known vs. Unknown 2. Imaginative starting point: all vs. Detail and 3. Focus Degree: vs focus. Out of focus the relationship of concepts defines the model for creativity in design.

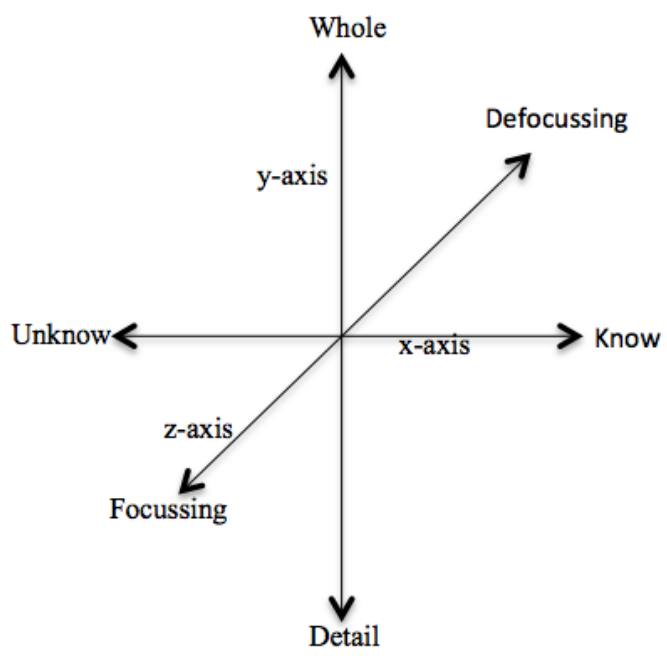

Fig. 1. A Prism of Schematization in Imagination Font: (Folkmann, 2010).

\section{Creativity (degree in Industrial design )}

In order to identify the factors that drive a creative personality in the industrial designers of the University Center UAEM Valle de Chalco, we took as a base the daily practice that is done in the trajectory of the students, from the first to the eighth semester in which creativity is worked for the development of industrial design projects, specifically in the subjects of design of products and systems, as well as considered the most relevant specific skills of the industrial designer (Sánchez, 2018), (see table 1), these skills facilitated the approach of this research. In addition, 10 out of 20 concepts applied in practice for product design were identified, weighted by level of importance by expert professors in the area of design and innovation. 
Table 1. Most relevant specific competences of the industrial designer

\begin{tabular}{|c|}
\hline $\begin{array}{l}\text { ipline concepts, as well as forms and structures in design concepts to apply } \\
\text { elements of form. }\end{array}$ \\
\hline $\begin{array}{l}\text { 2. Analyze and interpret the elements of the state of the art, the different areas, sustainability, ergonomics, } \\
\text { aesthetics, technology and market to integrate the elements based on design fundamentals, creativity, } \\
\text { perception and awareness for the development of design proposals. }\end{array}$ \\
\hline $\begin{array}{l}\text { 3. To interpret systemically the interrelation between human factors and other systems, from ergonomics } \\
\text { and anthropometry for their evaluation and application in the design of artifacts and industrial objects. }\end{array}$ \\
\hline $\begin{array}{l}\text { 4. Recognize and accept industrial design projects that guarantee sustainable development and sustainable } \\
\text { environmental, social, cultural and economic. }\end{array}$ \\
\hline $\begin{array}{l}\text { 5. Recognize and select the creative application of conventional and next-generation materials in specific } \\
\text { design problems. }\end{array}$ \\
\hline 6. Recognize the project process as a research method for the configuration of Industrial Design objects. \\
\hline $\begin{array}{l}\text { 7. Handle computer-assisted design programs for two- and three-dimensional graphic representation of } \\
\text { Industrial Design objects, using electronic and printed formats. }\end{array}$ \\
\hline $\begin{array}{l}\text { 8. Perceive, conceive and handle the transition of materials (paper, cardboard, foams, plastic laminates, } \\
\text { balsa wood, plaster, plasticine, etc.) for the three-dimensional representation of objects at any scale. }\end{array}$ \\
\hline $\begin{array}{l}\text { 9. Handle the means and tools to perform animations and virtual simulations of Industrial Design objects } \\
\text { with specialized software. }\end{array}$ \\
\hline $\begin{array}{l}\text { 10. Handle the means and tools to develop three-dimensional models, using stereolithographic printers or } \\
\text { computer-aided numerical control machining centers or equipment. }\end{array}$ \\
\hline $\begin{array}{l}\text { 11. To develop industrial design projects that guarantee sustainable development and environmental, social, } \\
\text { cultural and economic sustainability. }\end{array}$ \\
\hline
\end{tabular}

Font: Sánchez, $O(2018)$

The undergraduate teachers have worked on the design projects, considering that each one of the mentioned competencies requires creative actions. Therefore, it was decided to study the following 20 concepts applied in the classroom and identify the 10 most important in the creative process.

V1-Lineaments, V2 Activities, V3 Educate, V4 Barriers, V5 Intuition, V6
Imagination, V7 Creative teacher, V8 Critical capacity, V9 Attitude, V10
Techniques and methods, V11 Aptitude, V12 Representation, V13 Context,
V14 Research, V15 Experience, V16 Fantasy, V17 Audacity, V18 Ideas,
V19 Drawing, V20 Curiosity. (the assigned number is only by ordering)

To validate the information we worked with the "Hamming Distance". The purpose of using this tool was to detect the similarity between the real vectors and the estimated vectors. So it was possible to define the distance that exists between $A(x)$, vector of the real averages in each level of the variables suggested for the creative thinking of the industrial designer, and $\mathrm{B}(\mathrm{y})$ vector of the estimated averages in each level of these variables. 
Hamming distance

$$
\delta\left[\mu_{A(x)}, \mu_{B(y)}\right]=\frac{1}{n} \sum_{k=0}^{n}\left|\mathrm{x}_{\mathrm{k}}-\mathrm{y}_{\mathrm{k}}\right|
$$

$A(x)$ is the vector of the real averages at each level of the variables suggested for creative thinking in industrial design.

$B(y)$ is the vector of the estimated averages at each level of the variables suggested for creative thinking in industrial design.

It defines the attributes of set $A(x)$.

Defines the attributes of set $B(y)$.

$X k$ is the $k$-th attribute of set $A(x)$.

$n$ is the total of attributes.

The average distance established between the actual state derived from the research exercise applied to teachers and the ideal state found from the technique used was (1.75). The following graph represents it.

Table 1. Variable frequency

\begin{tabular}{|c|c|c|c|c|c|c|c|c|c|c|c|c|c|c|c|}
\hline Va. & N-RI & N-R & $-R 3$ & N-R4 & N-R5 & N-R6 & N-R7 & N-R8 & N-R9 & N-RI & Sum & Ve-Rea & Po. & Ve. Ide: & Po. \\
\hline V-1 & 6 & 4 & 2 & 0 & 1 & 1 & 0 & 0 & 0 & 0 & 14 & 1.4 & & 4.6 & \\
\hline V-2 & 3 & 2 & 3 & 1 & 1 & 0 & 0 & 0 & 0 & 0 & 10 & 2 & 8 & 1 & 8 \\
\hline V-3 & 5 & 4 & 3 & 0 & 0 & 0 & 0 & 0 & 0 & 0 & 12 & 2.8 & 4 & 1.2 & 9 \\
\hline$V-4$ & 0 & 3 & 4 & 4 & 0 & 1 & 0 & 0 & 0 & 0 & 12 & 2.8 & 5 & 1.2 & 9 \\
\hline V-5 & 0 & 0 & 0 & 2 & 3 & 1 & 2 & 0 & 0 & 0 & 8 & 2.2 & 7 & 0.8 & 6 \\
\hline V-6 & 1 & 2 & 2 & 1 & 1 & 1 & 0 & 0 & 0 & 0 & 8 & 1.2 & & 0.8 & 6 \\
\hline V-7 & 0 & 1 & 1 & 0 & 1 & 1 & 0 & 0 & 1 & 0 & 5 & 0.5 & & 0.5 & 3 \\
\hline V-8 & 0 & 0 & 0 & 2 & 2 & 2 & 0 & 1 & 0 & 0 & 7 & 1.3 & & 0.7 & 5 \\
\hline V-9 & 1 & 1 & 2 & 1 & 0 & 2 & 0 & 0 & 0 & 0 & 7 & 1.3 & & 0.7 & 5 \\
\hline V-10 & $\mathbf{0}$ & 0 & 0 & 5 & 0 & 2 & 2 & 0 & 1 & 0 & 10 & 4 & 2 & 1 & 8 \\
\hline V-11 & 0 & 0 & 1 & 0 & 3 & 0 & 0 & 2 & 0 & 1 & 7 & 1.3 & & 1.7 & \\
\hline V-12 & 0 & 0 & 0 & 0 & 1 & 1 & 3 & 1 & 1 & 0 & 7 & 2.3 & 6 & 0.7 & 5 \\
\hline V-13 & 0 & 0 & 0 & 0 & 0 & 1 & 2 & 0 & 0 & 0 & 3 & 1.7 & 9 & 0.3 & 2 \\
\hline V-14 & 0 & 1 & 0 & 0 & 1 & 2 & 5 & 6 & 2 & 0 & 17 & 4.3 & 1 & 1.7 & 10 \\
\hline V-15 & 0 & 0 & 0 & 0 & 0 & 0 & 1 & 2 & 2 & 2 & 7 & 1.3 & & 0.7 & 5 \\
\hline V-16 & 0 & 0 & 0 & 0 & 0 & 0 & 0 & 3 & 4 & 2 & 9 & 3.1 & 3 & 0.9 & 7 \\
\hline V-17 & 1 & 0 & 0 & 1 & 1 & 1 & 2 & 1 & 0 & 0 & 7 & 1.3 & & 0.7 & 5 \\
\hline V-18 & 0 & 0 & 0 & 0 & 0 & 2 & 0 & 0 & 2 & 1 & 5 & 1.5 & 10 & 0.5 & 3 \\
\hline V-19 & 1 & 0 & 0 & 1 & 0 & 0 & 0 & 0 & 0 & 0 & 2 & 0.8 & & 0.2 & 1 \\
\hline$V-20$ & 0 & 0 & 0 & 1 & 1 & 0 & 1 & 0 & 2 & 1 & 6 & $\begin{array}{c}1.4 \\
38.5 \\
1.75\end{array}$ & & $\begin{array}{c}0.6 \\
20.5 \\
1.025\end{array}$ & 4 \\
\hline
\end{tabular}

Font: Sánchez, $O$ (2018) 


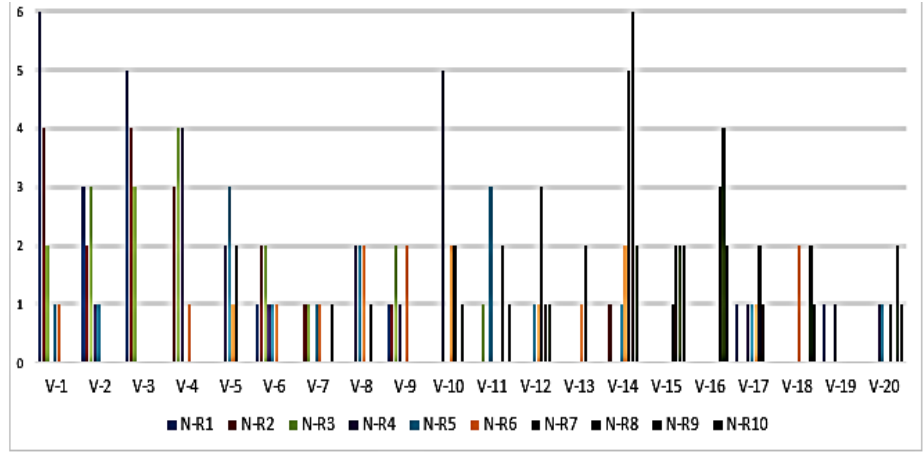

After the study identified the following 10 concepts by level of importance for creative thinking: 1-V14 Curiosity. 2-V10 Fantasy, 3-v16 Attitude, 4-V3 Ideas, 5-V4 Critical capacity, 6-V12 Imagination, 7-V5 Aptitude, 8-V2 Educate, 9-V13 Creative teacher, 10V18 Representation

\section{Conclusion}

Based on the foregoing, it can be concluded that the educator must have a profile and personality of creator to guide a working group or project, if the teacher limits or rejects free thought, will be hindering the first steps to develop and consolidate A creative personality in industrial design. For Berzbach (2013) The feeling of guilt is one of the greatest barriers to creative life.

\section{References}

Amabile, T (1997) Entrepreneurial creativity through motivational synergy Jour- nal of Creative Behavior Vol 31 pp $18 \mathrm{e} 26$

Basadur, M., \& Head, M. (2001). Team performance and satisfaction: A link to cognitive style within a process framework. The Journal of Creative Behavior, 35(4), 227e248. https://doi.org/10.1002/j.2162-6057.2001.tb01048.x.

Berzbach, F. (2013). Psicología para creativos: Primeros auxilios para conservar y sobrevivir en el trabajo..Gustavo Gili Sl. Barcelona. 
Cho, S., Holyoak, K. J., \& Cannon, T. D. (2007). Analogical reasoning in working memory: Resources shared among relational integration, interference resolution, and maintenance. Memory \& cognition, 35(6), 1445-1455.

Cox, T. H., \& Blake, S. (1991). Managing cultural diversity: Implications for organizational competitiveness. Academy of Management Perspectives, 5(3), 45-56.

Demirkan, H., \& Afacan, Y. (2012). Assessing creativity in design education: Analysis of creativity factors in the first-year design studio. Design Studies, 33(3), 262-278.

Damle, A., \& Smith, P. J. (2009). Biasing cognitive processes during design: The effects of color. Design Studies, 30(5), 521e540. http://doi.org/10.1016/ j.destud.2009.01.001

Folkmann, M. N. (2010). Enabling creativity. Imagination in design processes. In DS 66-2: Proceedings of the 1st International Conference on Design Creativity (ICDC 2010).

Fu, K., Chan, J., Cagan, J., Kotovsky, K., Schunn, C., \& Wood, K. (2013). The Meaning of "near" and "Far": The impact of structuring design databases and the effect of distance of analogy on design output. Journal of Mechanical Design, 135(2), 21007. http://doi.org/10.1115/1.4023158.

Gentner, D. (1983). Structure-mapping: A theoretical framework for analogy. Cognitive science, 7(2), 155-170.

Gilberto Leonardo, O. (2004). La definición del concepto de percepción en psicología con base en la teoría Gestalt. Revista de estudios sociales, (18), 89-96.

Goel, V and Pirolli, P (1989) Motivating the notion of generic design within information processing theory: the design problem space AI Magazine Vol 10 pp 19e36

Goel, V (1995) Sketches of thought MIT Press, Cambridge, MA

Goucher-Lambert, K., Moss, J., \& Cagan, J. (2019). A neuroimaging investigation of design ideation with and without inspirational stimuli-understanding the meaning of near and far stimuli. Design Studies, 60, 1-38.

Hamming, R. W. (1950). Error detecting and error correcting codes. Bell System technical journal, 29(2), pp.147-160.

Hoever, I. J., van Knippenberg, D., van Ginkel, W. P., \& Barkema, H. G. (2012). Fostering team creativity: Perspective taking as key to unlocking diversity's potential. Journal of Applied Psychology, 97(5), 982e996. https://doi.org/ 10.1037/a0029159.

Jansson, D. G., \& Smith, S. M. (1991). Design fixation. Design Studies, 12(1), 3e11. http://doi.org/10.1016/0142-694X(91)90003-F

Kim, M. H., Kim, Y. S., Lee, H. S., \& Park, J. A. (2007). An underlying cognitive aspect of design creativity: Limited Commitment Mode control strategy. Design Studies, 28(6), 585-604.

Kim, Y S and Kang, B G (2003) Personal characteristics and design-related perfor- mances in a creative engineering design course, in Proceedings of the 6th Asian Design Conference, Tsukuba, Japan 
Reflections on the creative process, analysis of strategic models for the development of creative thinking in the Industrial Designer

Kim, Y. S., Kim, M. H., \& Jin, S. T. (2005, January). Cognitive characteristics and design creativity: an experimental study. In ASME 2005 international design engineering technical conferences and computers and information in Engineering Conference (pp. 309-317). American Society of Mechanical Engineers Digital Collection.

Kirton, M. J. (2003). Adaption e innovation. In The context of diversity and change. Innovation. https://doi.org/10.4324/9780203695005.

Krawczyk, D. C., Morrison, R. G., Viskontas, I., Holyoak, K. J., Chow, T. W., Mendez, M. F., et al. (2008). Distraction during relational reasoning: The role of prefrontal cortex in interference control. Neuropsychologia, 46(7), 2020e2032. http://doi.org/10.1016/j.neuropsychologia.2008.02.001.

Kurtzberg, T. R., \& Amabile, T. M. (2001). From guilford to creative synergy: Opening the black box of team-level creativity. Creativity Research Journal, 13(3e4), $285 \mathrm{e} 294$. https://doi.org/10.1207/S15326934CRJ1334_06.

Linsey, J. S., \& Viswanathan, V. K. (2014). Overcoming cognitive challenges in bioinspired design and analogy. In Biologically Inspired Design (pp. 221-244). Springer, London.

Lubart, T I (1994) Creativity in R J Sternberg (ed) Thinking and problem solving Academic Press, NY pp 289e332

Mello, A. L., \& Rentsch, J. R. (2015). Cognitive diversity in teams: A multidisciplinary review. Small Group Research, 46(6), 623-658.

Menold, J., \& Jablokow, K. (2019). Exploring the effects of cognitive style diversity and self-efficacy beliefs on final design attributes in student design teams. Design Studies, 60, 71-102.

Mohammed, S., \& Angell, L. C. (2004). Surface- and deep-level diversity in work- groups: Examining the moderating effects of team orientation and team process on relationship conflict. Journal of Organizational Behavior, 25(8), 1015e1039. https://doi.org/10.1002/job.293

Moreno, A., Domingo, J. M. C., \& García, F. G. (2014). La aleatoriedad en profesores de biología y de matemática en formación: análisis y contraste de significados. Revista Eureka sobre Enseñanza y Divulgación de las Ciencias, 11(2), 198-215.

Park, J. A., Kim, Y. S., \& Cho, J. Y. (2006). Visual reasoning as a critical attribute in design creativity. In Proceedings of International Design Research Symposium.

Sánchez, O. (2018). Identificación de las competencias específicas más relevantes del diseñador industrial: ejercicio para el desarrollo de un plan curricular (Ed. Pearson) México.

Shroyer, K., Lovins, T., Turns, J., Cardella, M. E., \& Atman, C. J. (2018). Timescales and ideaspace: An examination of idea generation in design practice. Design Studies, 57, 9-36.

Sternberg, R J (2001) What is the common thread of creativity? Its dialectical relation to intelligence and wisdom American Psychologist Vol 56 pp 360e362

Sternberg, R. J., \& Grigorenko, E. L. (1997). Are cognitive styles still in style? American 
Psychologist, 52(7), 700e712. https://doi.org/10.1037/0003-066X.52.7.700.

Sternberg, R J and Lubart, T I (1996) Investing in creativity American Psychologist Vol 51 No 7 pp $677 \mathrm{e} 688$

Wharton, C. M., Grafman, J., Flitman, S. S., Hansen, E. K., Brauner, J., Marks, A, et al. (2000). Toward neuroanatomical models of analogy: A posi- tron emission tomography study of $\begin{array}{llll}\text { analogicamapping. } & \text { Cognitive } & \text { Psychology, } & \text { 40(3), }\end{array}$ http://doi.org/10.1006/cogp.1999.0726.

Williams, A., Ostwald, M. J., \& Askland, H. H. (2010). Creativity, design and education: Theories, positions and challenges. Australian Learning \& Teaching Council.

Wilson, J. O., Rosen, D., Nelson, B. A., \& Yen, J. (2010). The effects of biological examples in idea generation. Design Studies, 31(2), 169e186. http://doi.org/ 10.1016/j.destud.2009.10.003. 